\title{
Climatic Disasters from the 7th to the 12th Centuries: Considerations of Influences on Climatic Disasters by Local Climates in Nara and Kyoto
}

\author{
MARUMOTO Miki* and FUKUOKA Yoshitaka** \\ *Nihon University. \\ ** Rissho University. \\ E-mail: miki-m@w6.dion.ne.jp*
}

Received January 26, 2015; Accepted September 5, 2016

\begin{abstract}
Many natural disasters have occurred in Japan since ancient times. It corresponds to the "Medieval climate anomaly (MCA)" or "Medieval warm period (MWP)" which existed from the 9th to the 12th centuries, as pointed out by the climatologists in Europe and U.S.A. In the history of Japan, however, this period is called "ancient period". In this study, the authors collected 1,220 records of climatic disasters and constructed a chronology of climatic disasters in Japan from the 7th to the 12th centuries. Furthermore, their secular changes of kinds and regions were clarified. It can be said that number of climatic disasters increased remarkably during the second half of the 9th century, the early 11th century and the latter half of the 12th century. Concerning kinds of climatic disasters, the most common disaster was storm (26.1\%) and the next was drought (19.8\%). As for place names related to all climatic disasters, the most frequent place was Kyoto (48.3\%) and the second was Nara (7.9\%). From these investigations, it was clarified that drought was the major climatic disaster before the 9th century. On the other hand, disaster caused by too much rain prevailed from the 9th century. But the regions with records on climatic disasters clearly changed from Nara to Kyoto at the end of the 8th century. Therefore, the authors proposed that local climates in Nara and Kyoto influenced the change of climatic disasters.
\end{abstract}

Key words Paleoclimate, drought, flood, regional features, Nara, Kyoto

\section{Introduction}

It has been recognized that climatic disasters tend to increase when air temperature fluctuates violently. Even nowadays, social anxiety is increasing in relation to climatic disasters caused by global warming. Concerning the effects of global warming, it is expected in Japan that the numbers of extremely hot days (with a maximum temperature above $35^{\circ} \mathrm{C}$ ), unusual extremes of rainfall, and so on will increase (Japan Meteorological Agency 2013; IPCC and Ministry of the Environment, Government of Japan 2013).

Similarly, the climate in Japan was warmer corresponding with "Medieval warm period (MWP)" from the 9th to the 12th centuries. For example, Maejima and Tagami (1986) clarified by analyzing "Nihon kishoshiryo" that the 7 th to the 9th centuries were a cool period and the 10th to the 14th centuries were a warm period. In addition, the climate reconstructed by the records of cherry blossoming was warm around the 10th century (Sekiguchi 1969; Yamamoto 1976; Aono 2013). Moreover, Yoshino (2009) argued that the warm period with various scale of fluctuations continued from the 4 th to the 10th centu- ries. Mizukoshi $(2004,2006,2008,2010,2012,2014)$ collected diurnal weather records from the 11th to the 16th centuries in Japan and he referred that the 11th and the 12th centuries were relatively warm periods. According to Kitagawa and Matsumoto (1998) who analyzed carbon isotope variations in tree rings of Yakusugi cedars, the estimated temperature deviations from the 8th to the 12th centuries were $1.0^{\circ} \mathrm{C}$ higher than the average during the last 2,000 years.

In this period, it is historically known that serious natural disasters occurred in Japan. Seismologically, the Jogan Tsunami in 869 has been studied from remains, sediments and old documents by Okamura (2012) and Sangawa (2013) and so on. In "Nihon sandai jitsuroku", it was noted that Mt. Fuji erupted in 864 and it was one of the three major volcanic eruptions (Nishikawa 2002). Hotate (2012) concluded that the 7th and 8th centuries can be regarded as "a peculiar period with earthquakes, global warming and pandemics".

From the 7th to the 12th centuries, Japan also suffered from various climatic disasters such as heavy rains, floods, droughts, and the like. Kusakabe constructed the chronology of climatic disasters from the 6th to the 
19th centuries according to provinces of Shikoku, Kanto, Chubu and Mie, Kinki, Chugoku and Ou of Japan by using "Nihon kishoshiryo" (Kusakabe 1969, 1973a, 1973b, 1975a, 1975b, 1975c, 1975d, 1977, 1978, 1981). Focusing on Kinki province in these results shows, the drought was the major climatic disaster in the 7 th and 8 th centuries where as floods caused by much rain increased in the 9th century. From the 10th to the 11th centuries, drought increased again while flood related to typhoon increased in the 12th century. Moreover, Nishikawa (1968) made a table of climatic disasters from the 6th to the 20th centuries based on "Nihonsaiishi" and obtained that the most remarkable disaster was plague and the second one was drought from the 6 th to the 16 th centuries.

However, these studies showed a lesser number of climatic disasters because these studies were analyzed by only one document and were not referred sufficiently to local climates. Furthermore, Maejima and Tagami (1986) pointed out the problem that the paleoclimate reconstructed from historical documents is reflect only local climate. Therefore, collecting as many cases of climatic disasters from historical documents as possible is important for paleoclimate study and it is necessary to clarify by more detailed information. Besides, clarification of climatic disasters during the 7 th to the 12 th centuries is valuable for predicting the natural and human impacts by global warming at the present.

The purposes of this study are to construct a chronology of climatic disasters by using a greater number of historical documents and to clarify changes of kinds and regions of climatic disasters from the 7 th to the 12 th centuries especially making point of Nara and Kyoto where most of the historical documents were concentrated. We will also discuss geographically that differences in the respective local climates in Nara and Kyoto could reflect climatic disasters.

\section{Study Method}

The records of climatic disasters in Japan from ancient

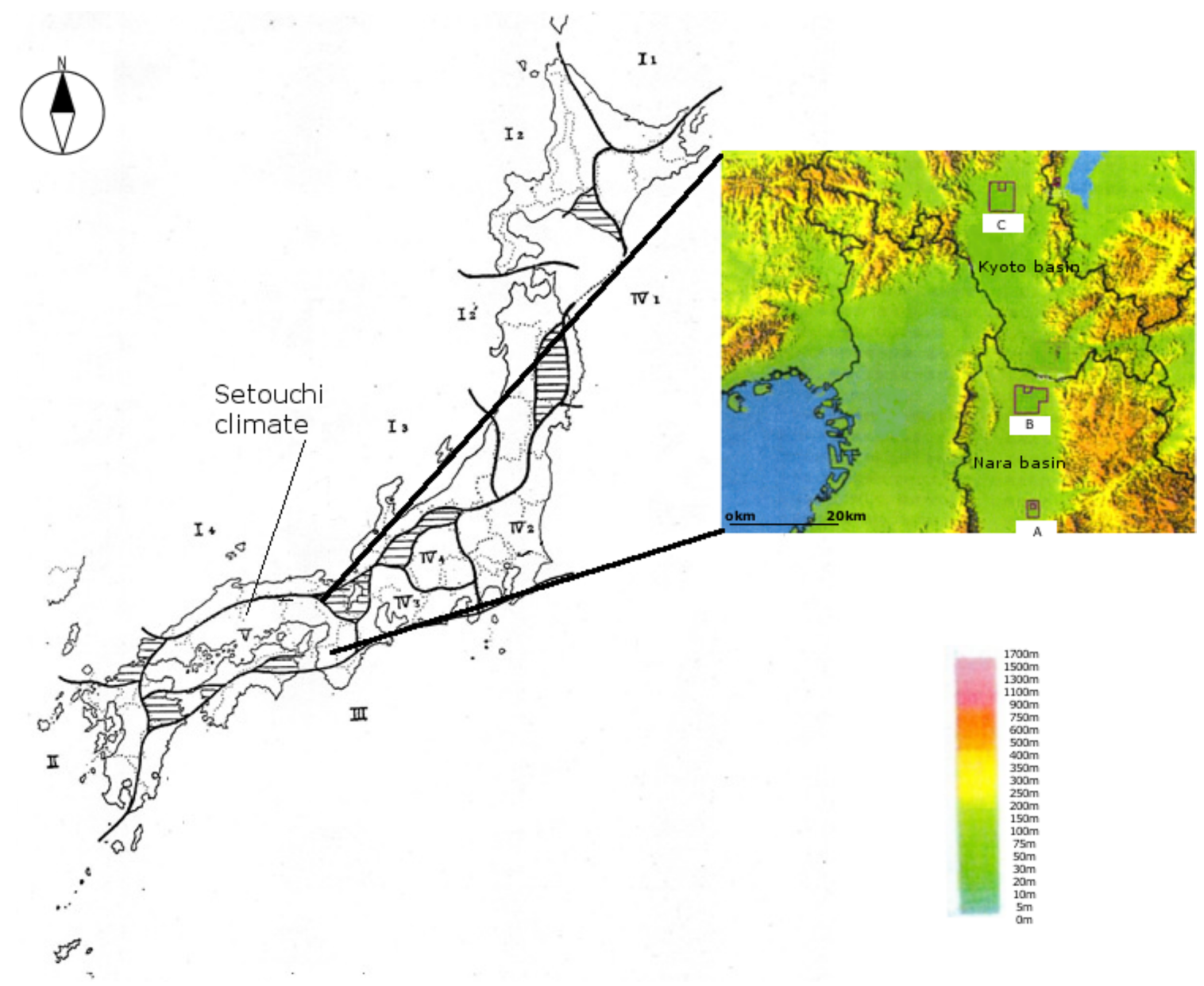

Figure 1. The place of Nara and Kyoto basins.

A, B and C in this figure present the capital of Asuka and Fujiwarakyo (593-710), the capital of Heijokyo (710-784) and the capital of Heiankyo (794-1192) respectively ${ }^{3}$. This figure was recomposed from the climatic divisions by Sekiguchi (1959) and capital locations by Geospatial Information Authority of Japan (2000). 
times have been found in some historical documents, such as "Nihon shoki", "Fuso ryakuki", and "Nihon sandai jitsuroku". Furthermore, these records have been edited in several meteorological archives. First, the authors collect the data and construct a chronology of climatic disasters from the 7th to the 12th centuries from the following meteorological archives: (1) "Nihon no kisho shiryo (The Central Meteorological Observatory and The Imperial Marine Observatory 1976)", (2) "Nihon kanbatsu rin-u shiryo (Arakawa et al. 1964)", (3) "Nihon no tensai chihen (The Civic Section of Tokyo Metropolitan Government 1976)", (4) "Naraken kisho saigai shi (Aoki 1956)" and (5) "Kyoto kisho saigai nempyo (Kyoto Local Meteorological Office 1951)". These archives include records of climatic disasters from the prefectural histories, documents of temples and shrines, diaries of prayers for rains and the like. In some cases, place names, sources and detailed contents of climatic disasters are also collected.

Secondly, these data are classified according to kinds and regions of climatic disasters. Namely, they are grouped into 9 categories according to their kinds: (1) storm, (2) flood, (3) long rain, (4) thunder storm, (5) whirlwind, (6) drought, (7) hail storm, (8) heavy snow and (9) frost. In these climatic disasters, the cases of storm, flood, long rain and thunder storm may be difficult to distinguish from each other because storm and long rain could have been accompanied with flood. In this paper, we classified these data based on the way of "Nihon no kisho shiryo" ${ }^{1}$. As to the place names where climatic disasters occurred, the old place names are arranged into 6 categories as follows:

(1) "Nara" includes its old names "Yamato koku" and
"Yamato".

(2) "Kyoto" includes its old names "Yamashiro koku" and "Yamashiro".

(3) "Kinki District" includes "Kinai" and "Kinki shokoku", but excludes the cases classified as (1) or (2). It means that climatic disasters occurred in wide area such as Kyoto, Nara and neighboring region simultaneously.

(4) "All provinces" include "Shokoku" and "Zenkoku", but exclude the cases classified as (1), (2) or (3).

(5) Place names which do not refer to (1), (2), (3) and (4) are classified into "others".

(6) Nameless places are grouped into "Unknown".

If the same kinds, place names and dates of climatic disasters were obtained from some of five archives, the authors counted them as one disaster.

\section{Results}

\section{Features of climatic disasters from the 7th to the 12th centuries}

The authors collected 1,220 climatic disasters and 1,281 place names in this study. This data is more than the similar studies of Kusakabe (1977) and Nishikawa (1968) who obtained 203 and 510 data respectively during the same period $^{2}$.

Figure 2 shows the secular change of climatic disasters comparing with the estimated temperature deviations reconstructed from tree ring analysis by Kitagawa and Matsumoto (1998). As shown in Figure 2, climatic disasters tend to increase when estimated temperature deviations are greater. Three peaks in the number of climatic

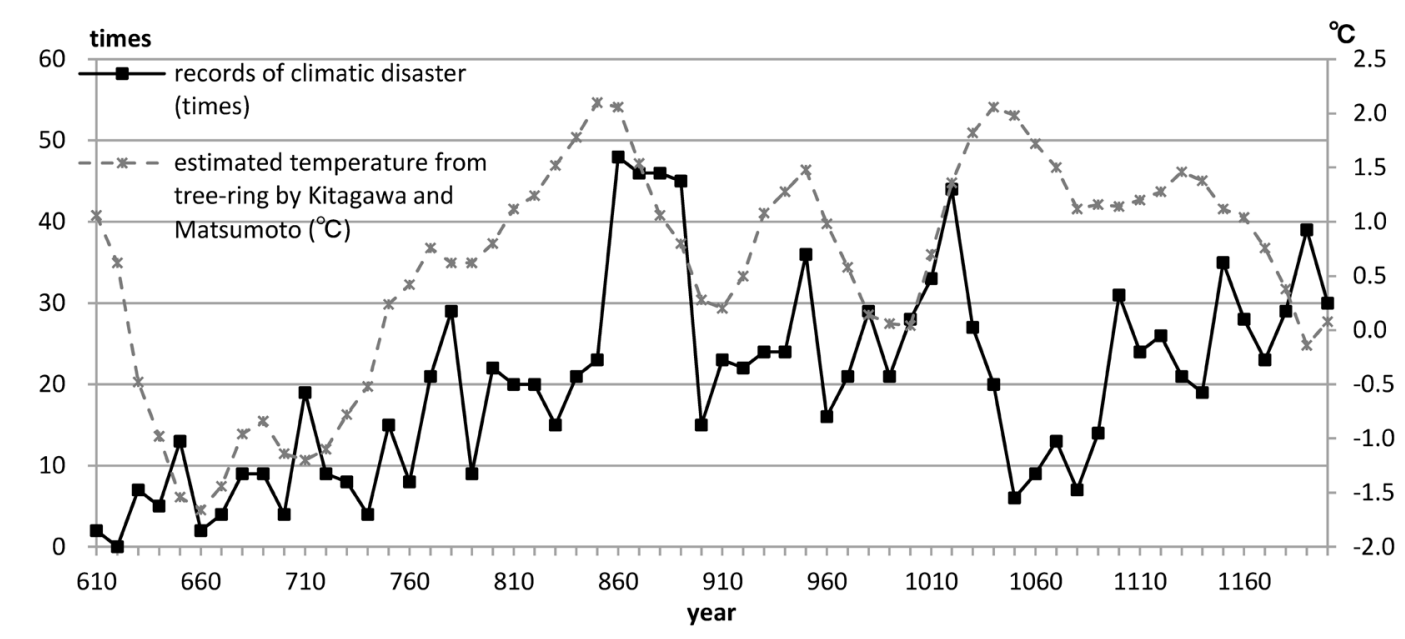

Figure 2. Secular change of estimated temperature deviations by Kitagawa and Matsumoto (1998) and climatic disasters from the 7 th to the 12 th centuries.

On these estimated temperature deviations, the authors read the data from the figures on the tree ring analysis of carbon isotope by Kitagawa and Matsumoto (1998) and calculated five decadal moving averages of the estimated temperature deviations in order to smooth out the fluctuation of temperature deviations. 
disasters were found in this figure. They are the periods from the latter half of the 9th century, the first half of the 11th century and the latter half of the 12th century. Around the middle of the 11th century, there was a significant decrease in number of climatic disasters. In this respect, Kawasumi (2004) and Takahashi (2012) stated that the level of riverbed in the Kamogawa River had dropped from the end of the 10th to the early period of the 12th centuries and this would keep the river from overflowing. From the database of "Historiographical Institute, the University of Tokyo", Katahira (2010) clarified that the number of floods in Kyoto was at a minimum around the latter part of the 11th century.

The correlation coefficient between the number of climatic disasters and the estimated temperature deviations is 0.35 , which is a positive correlation at the significance level of $5 \%$.

Table 1 summarizes the chronology by the number of climatic disasters counted for every decade on their kinds and percentages from the 7th to the 12th centuries. In the 7th century, the number of climatic disasters is 55. Drought (30.9\%) is most significant disaster and storm $(18.2 \%)$ is the next. In the 8th century, the records increased by 144 and drought and storm remarkably occurred in the same percentage (29.9\%) respectively. In the 9th century, the records rapidly increased by 299 , in which significant disasters are storm and thunder storm (19.7\%) respectively. In the 10th century, the records decreased by 244 . In the 11 th century, climatic disaster dwindled to 204 however, they rose to 274 in the 12th century. The most remarkable disaster was storm (31.4\%) in the 11th century and this condition continued until the 12 th century.

\section{Kinds and regions of climatic disasters and their secular changes}

Figures 3-a and 3-b show the ratios of kinds and regions of climatic disasters from the 7 th to the 12th centuries. Concerning all climatic disasters from the 7th to the 12th centuries, the most common climatic disaster is the storm (26.1\%), next, the drought (19.8\%) and third, the thunder storm (18.9\%). The disasters are related to rain such as the storm, flood and long rain, occupy about half of them. On the other hand, the most common region is Kyoto making up $48.3 \%$. The second is Nara $(7.9 \%)$ and third is the Kinki District (4.1\%). Some of the other place names and its percentages are Ise (Mie Prefecture, 3.8\%), Kamakura (Kanagawa Prefecture, $0.7 \%$ ), Kii (Wakayama Prefecture, 0.5\%), Omi (Shiga Prefecture, 0.5\%), Kawachi (Osaka Prefecture, 0.5\%) and
Kyushu District (0.5\%). From these results, it might be inferred that many records of climatic disasters had been concentrated in the capital around that time.

Figure 4-a shows the secular change of percentages (\%) of climatic disasters. Drought accounts for the greatest percentage before the early half of the 9th century and the early half of the 10th century after then they decrease gradually with more or less fluctuations. Conversely, disasters caused by heavy rain represents the majority of disasters after the latter half of the 9th century except the early half of the 10th century. According to Kusakabe (1977) stated that drought was more than half of climatic disasters in the 7th and the 8th centuries, in contrast to rain and flood damages in the 10th to the 12th centuries. Although the present study comes to a similar conclusion as secular change, we want to draw attention to the regional change of climatic disasters. As shown in Figure 4 -b, the percentage of disasters is remarkably covered by Nara until the latter part of the 8th century. On the contrary, historical records in Kyoto occupy half of them, whereas the ones in Nara nearly vanished from the 9th century because historical records tended to concentrate in the capital city of the time. That is, Nara was the capital of Japan from 593 to 784 and Kyoto was the capital of Japan from 794 to $1192^{3}$. From this analysis we can conclude that there were frequent droughts and records of climatic disasters centered in Nara before the 9th century while there were more disasters caused by much rain and records of climatic disasters concentrated in Kyoto from the 9 th to the 12th centuries.

Figure 5 compared the percentages of climatic disasters from the 7th to the 12th centuries in Nara with those of Kyoto. Droughts in Nara make up 23.8\%, in contrast to Kyoto which shows only $7.4 \%$. On the other hand, concerning flood, Kyoto shows about $10 \%$ higher than Nara. Climatic disasters caused especially by rainfall are more than $70 \%$ in Kyoto.

\section{Discussion}

\section{Influences of local climate on climatic disasters}

As mentioned above, drought frequent occurred before the early half of the 9th century and the early half of the 10th century while disaster caused by heavy rain occurred frequently after the latter half of the 9th century except the early half of the 10th century. However, the concentrated region of the climatic disasters shifted from Nara to Kyoto with the relocation of the capital from Nara to Kyoto in the latter part of the 8th century. Tanioka (2010) obtained that drought was the major climatic disaster 
Table 1. Contents of climatic disasters from the 7 th to the 12th centuries

\begin{tabular}{|c|c|c|c|c|c|c|c|c|c|c|}
\hline & Storm & Flood & Long rain & Thunder storm & Whirl wind & Drought & Hail storm & Heavy snow & Frost & Subtotal \\
\hline \multirow{2}{*}{$601 \sim 610$} & 0 & 1 & 0 & 0 & 0 & 1 & 0 & 0 & 0 & 2 \\
\hline & $(0.0)$ & $(50.0)$ & $(0.0)$ & $(0.0)$ & $(0.0)$ & $(50.0)$ & $(0.0)$ & $(0.0)$ & $(0.0)$ & $(100.0)$ \\
\hline \multirow{2}{*}{$611 \sim 620$} & 0 & 0 & 0 & 0 & 0 & 0 & 0 & 0 & 0 & 0 \\
\hline & $(0.0)$ & $(0.0)$ & $(0.0)$ & $(0.0)$ & $(0.0)$ & $(0.0)$ & $(0.0)$ & $(0.0)$ & $(0.0)$ & $(0.0)$ \\
\hline \multirow{2}{*}{$621 \sim 630$} & 0 & 1 & 1 & 0 & 0 & 2 & 2 & 0 & 1 & 7 \\
\hline & $(0.0)$ & $(14.3)$ & $(14.3)$ & $(0.0)$ & $(0.0)$ & $(28.6)$ & $(28.6)$ & $(0.0)$ & $(14.3)$ & $(100.0)$ \\
\hline \multirow{2}{*}{$631 \sim 640$} & 2 & 1 & 1 & 0 & 0 & 1 & 0 & 0 & 0 & 5 \\
\hline & $(40.0)$ & $(20.0)$ & $(20.0)$ & $(0.0)$ & $(0.0)$ & $(20.0)$ & $(0.0)$ & $(0.0)$ & $(0.0)$ & (100.0) \\
\hline \multirow{2}{*}{$641 \sim 650$} & 2 & 1 & 1 & 1 & 0 & 1 & 6 & 0 & 1 & 13 \\
\hline & $(15.4)$ & $(7.7)$ & (7.7) & (7.7) & $(0.0)$ & $(7.7)$ & $(46.2)$ & $(0.0)$ & (7.7) & (100.0) \\
\hline $651 \sim 660$ & $(0.0)$ & $(50.0)$ & $(0.0)$ & $(0.0)$ & $(0.0)$ & $(50.0)$ & $(0.0)$ & $(0.0)$ & $(0.0)$ & $(100.0)$ \\
\hline \multirow{2}{*}{$661 \sim 670$} & 0 & 1 & 0 & 2 & 0 & 0 & 0 & 1 & 0 & 4 \\
\hline & $(0.0)$ & $(25.0)$ & $(0.0)$ & $(50.0)$ & $(0.0)$ & $(0.0)$ & $(0.0)$ & $(25.0)$ & $(0.0)$ & $(100.0)$ \\
\hline \multirow{2}{*}{$671 \sim 680$} & 3 & 1 & 0 & 0 & 0 & 4 & 1 & 0 & 0 & 9 \\
\hline & (33.3) & $(11.1)$ & (0.0) & (0.0) & (0.0) & $(44.4)$ & $(11.1)$ & (0.0) & (0.0) & $(100.0)$ \\
\hline \multirow{2}{*}{$681 \sim 690$} & 2 & 0 & 0 & 1 & 0 & 6 & 0 & 0 & 0 & 9 \\
\hline & $(22.2)$ & $(0.0)$ & $(0.0)$ & $(11.1)$ & $(0.0)$ & $(66.7)$ & $(0.0)$ & $(0.0)$ & $(0.0)$ & $(100.0)$ \\
\hline \multirow{2}{*}{$691 \sim 700$} & 1 & 2 & 0 & 0 & 0 & 1 & 0 & 0 & 0 & 4 \\
\hline & $(25.0)$ & $(50.0)$ & $(0.0)$ & $(0.0)$ & $(0.0)$ & $(25.0)$ & $(0.0)$ & $(0.0)$ & $(0.0)$ & $(100.0)$ \\
\hline The 7th century & 10 & 9 & 3 & 4 & 0 & 17 & 9 & 1 & 2 & 55 \\
\hline \multirow{2}{*}{$701 \sim 710$} & 7 & 0 & 3 & 2 & 0 & 7 & 0 & 0 & 0 & 19 \\
\hline & $(36.8)$ & $(0.0)$ & (15.8) & $(10.5)$ & $(0.0)$ & $(36.8)$ & $(0.0)$ & $(0.0)$ & $(0.0)$ & $(100.0)$ \\
\hline \multirow{2}{*}{$711 \sim 720$} & 5 & 0 & 0 & 0 & 0 & 4 & 0 & 0 & 0 & 9 \\
\hline & $(55.6)$ & $(0.0)$ & $(0.0)$ & (0.0) & $(0.0)$ & $(44.4)$ & $(0.0)$ & $(0.0)$ & $(0.0)$ & $(100.0)$ \\
\hline \multirow{2}{*}{$721 \sim 730$} & 1 & 2 & 0 & 3 & 1 & 1 & 0 & 0 & 0 & 8 \\
\hline & $(12.5)$ & $(25.0)$ & $(0.0)$ & $(37.5)$ & $(12.5)$ & $(12.5)$ & $(0.0)$ & $(0.0)$ & $(0.0)$ & $(100.0)$ \\
\hline \multirow{2}{*}{$731 \sim 740$} & 1 & 0 & 0 & 0 & 0 & 3 & 0 & 0 & 0 & 4 \\
\hline & $(25.0)$ & $(0.0)$ & $(0.0)$ & $(0.0)$ & $(0.0)$ & $(75.0)$ & $(0.0)$ & $(0.0)$ & $(0.0)$ & $(100.0)$ \\
\hline \multirow{2}{*}{$741 \sim 750$} & 3 & 1 & 1 & 3 & 0 & 6 & 1 & 0 & 0 & 15 \\
\hline & $(20.0)$ & $(6.7)$ & $(6.7)$ & $(20.0)$ & $(0.0)$ & $(40.0)$ & (6.7) & $(0.0)$ & $(0.0)$ & $(100.0)$ \\
\hline \multirow{2}{*}{$751 \sim 760$} & 5 & 0 & 0 & 0 & 1 & 0 & 0 & 2 & 0 & 8 \\
\hline & $(62.5)$ & $(0.0)$ & $(0.0)$ & $(0.0)$ & (12.5) & $(0.0)$ & $(0.0)$ & $(25.0)$ & $(0.0)$ & (100.0) \\
\hline \multirow{2}{*}{$761 \sim 770$} & 4 & 4 & 1 & 1 & 0 & 10 & 1 & 0 & 0 & 21 \\
\hline & $(19.0)$ & $(19.0)$ & (4.8) & (4.8) & $(0.0)$ & $(47.6)$ & (4.8) & $(0.0)$ & $(0.0)$ & $(100.0)$ \\
\hline \multirow{2}{*}{$771 \sim 780$} & 11 & 3 & 1 & 6 & 0 & 6 & 2 & 0 & 0 & 29 \\
\hline & $(37.9)$ & $(10.3)$ & (3.4) & $(20.7)$ & $(0.0)$ & $(20.7)$ & (6.9) & $(0.0)$ & $(0.0)$ & $(100.0)$ \\
\hline \multirow{2}{*}{$781 \sim 790$} & 2 & 2 & 0 & 2 & 0 & 3 & 0 & 0 & 0 & 9 \\
\hline & $(22.2)$ & $(22.2)$ & $(0.0)$ & $(22.2)$ & (0.0) & (33.3) & $(0.0)$ & $(0.0)$ & $(0.0)$ & $(100.0)$ \\
\hline \multirow{2}{*}{$791 \sim 800$} & 4 & 5 & 1 & 3 & 0 & 3 & 2 & 4 & 0 & 22 \\
\hline & $(18.2)$ & $(22.7)$ & (4.5) & (13.6) & $(0.0)$ & (13.6) & (9.1) & $(18.2)$ & $(0.0)$ & $(100.0)$ \\
\hline The 8th century & $(29.9)$ & $(11.8)$ & (4.9) & (13.9) & (1.4) & $(29.9)$ & $(4.2)$ & $(4.2)$ & $(0.0)$ & $(100.0)$ \\
\hline
\end{tabular}


Table 1. Continued

\begin{tabular}{|c|c|c|c|c|c|c|c|c|c|c|}
\hline & Storm & Flood & Long rain & Thunder storm & Whirl wind & Drought & Hail storm & Heavy snow & Frost & Subtotal \\
\hline \multirow{2}{*}{$801 \sim 810$} & 5 & 3 & 4 & 0 & 0 & 5 & 2 & 1 & 0 & 20 \\
\hline & $(25.0)$ & $(15.0)$ & $(20.0)$ & $(0.0)$ & $(0.0)$ & $(25.0)$ & $(10.0)$ & $(5.0)$ & $(0.0)$ & $(100.0)$ \\
\hline \multirow{2}{*}{$811 \sim 820$} & 2 & 2 & 2 & 1 & 1 & 7 & 1 & 4 & 0 & 20 \\
\hline & $(10.0)$ & $(10.0)$ & (10.0) & (5.0) & $(5.0)$ & (35.0) & (5.0) & (20.0) & $(0.0)$ & $(100.0)$ \\
\hline \multirow{2}{*}{$821 \sim 830$} & 1 & 2 & 3 & 3 & 0 & 5 & 0 & 1 & 0 & 15 \\
\hline & $(6.7)$ & $(13.3)$ & $(20.0)$ & (20.0) & $(0.0)$ & (33.3) & $(0.0)$ & $(6.7)$ & $(0.0)$ & $(100.0)$ \\
\hline \multirow{2}{*}{$831 \sim 840$} & 7 & 2 & 1 & 4 & 1 & 6 & 0 & 0 & 0 & 21 \\
\hline & (33.3) & $(9.5)$ & $(4.8)$ & $(19.0)$ & $(4.8)$ & $(28.6)$ & $(0.0)$ & $(0.0)$ & $(0.0)$ & $(100.0)$ \\
\hline \multirow{2}{*}{$841 \sim 850$} & 3 & 5 & 2 & 4 & 1 & 3 & 1 & 3 & 1 & 23 \\
\hline & $(13.0)$ & $(21.7)$ & (8.7) & (17.4) & (4.3) & $(13.0)$ & $(4.3)$ & $(13.0)$ & (4.3) & $(100.0)$ \\
\hline \multirow{2}{*}{$851 \sim 860$} & 14 & 11 & 1 & 10 & 1 & 3 & 2 & 3 & 3 & 48 \\
\hline & $(29.2)$ & $(22.9)$ & (2.1) & (20.8) & (2.1) & (6.3) & $(4.2)$ & (6.3) & (6.3) & $(100.0)$ \\
\hline \multirow{2}{*}{$861 \sim 870$} & 13 & 3 & 9 & 7 & 0 & 8 & 1 & 1 & 4 & 46 \\
\hline & $(28.3)$ & (6.5) & (19.6) & $(15.2)$ & $(0.0)$ & (17.4) & $(2.2)$ & $(2.2)$ & $(8.7)$ & $(100.0)$ \\
\hline \multirow{2}{*}{$871 \sim 880$} & 5 & 3 & 7 & 14 & 3 & 7 & 1 & 5 & 1 & 46 \\
\hline & $(10.9)$ & (6.5) & (15.2) & (30.4) & (6.5) & (15.2) & (2.2) & $(10.9)$ & $(2.2)$ & $(100.0)$ \\
\hline \multirow{2}{*}{$881 \sim 890$} & 6 & 4 & 9 & 15 & 3 & 2 & 0 & 4 & 2 & 45 \\
\hline & $(13.3)$ & $(8.9)$ & $(20.0)$ & (33.3) & (6.7) & (4.4) & $(0.0)$ & (8.9) & $(4.4)$ & $(100.0)$ \\
\hline \multirow{2}{*}{$891 \sim 900$} & 3 & 4 & 1 & 1 & 1 & 3 & 0 & 2 & 0 & 15 \\
\hline & $(20.0)$ & $(26.7)$ & (6.7) & $(6.7)$ & $(6.7)$ & $(20.0)$ & $(0.0)$ & $(13.3)$ & $(0.0)$ & $(100.0)$ \\
\hline \multirow{2}{*}{ The 9th century } & 59 & 39 & 39 & 59 & 11 & 49 & 8 & 24 & 11 & 299 \\
\hline & $(19.7)$ & (13.0) & (13.0) & $(19.7)$ & $(3.7)$ & $(16.7)$ & (2.7) & (8.0) & (3.7) & $(100.0)$ \\
\hline \multirow{2}{*}{$901 \sim 910$} & 4 & 3 & 5 & 4 & 0 & 7 & 0 & 0 & 0 & 23 \\
\hline & $(17.4)$ & (13.0) & (21.7) & (17.4) & $(0.0)$ & $(30.4)$ & $(0.0)$ & $(0.0)$ & $(0.0)$ & $(100.0)$ \\
\hline \multirow{2}{*}{$911 \sim 920$} & 6 & 2 & 2 & 2 & 0 & 7 & 3 & 0 & 0 & 22 \\
\hline & $(27.3)$ & (9.1) & $(9.1)$ & (9.1) & $(0.0)$ & $(31.8)$ & (13.6) & $(0.0)$ & $(0.0)$ & $(100.0)$ \\
\hline \multirow{2}{*}{$921 \sim 930$} & 5 & 5 & 2 & 4 & 1 & 6 & 0 & 1 & 0 & 24 \\
\hline & $(20.8)$ & $(20.8)$ & (8.3) & $(16.7)$ & $(4.2)$ & $(25.0)$ & $(0.0)$ & (4.2) & $(0.0)$ & $(100.0)$ \\
\hline \multirow{2}{*}{$931 \sim 940$} & 4 & 2 & 3 & 6 & 1 & 5 & 0 & 2 & 1 & 24 \\
\hline & $(16.7)$ & (8.3) & $(12.5)$ & $(25.0)$ & $(4.2)$ & (20.8) & $(0.0)$ & (8.3) & $(4.2)$ & $(100.0)$ \\
\hline \multirow{2}{*}{$941 \sim 950$} & 8 & 3 & 10 & 4 & 0 & 8 & 0 & 2 & 1 & 36 \\
\hline & $(22.2)$ & (8.3) & (27.8) & $(11.1)$ & $(0.0)$ & $(22.2)$ & $(0.0)$ & $(5.6)$ & $(2.8)$ & $(100.0)$ \\
\hline \multirow{2}{*}{$951 \sim 960$} & 4 & 1 & 2 & 2 & 0 & 6 & 0 & 0 & 1 & 16 \\
\hline & $(25.0)$ & (6.3) & $(12.5)$ & $(12.5)$ & $(0.0)$ & $(37.5)$ & $(0.0)$ & $(0.0)$ & (6.3) & $(100.0)$ \\
\hline \multirow{2}{*}{$961 \sim 970$} & 4 & 6 & 5 & 3 & 0 & 3 & 0 & 0 & 0 & 21 \\
\hline & $(19.0)$ & (28.6) & $(23.8)$ & $(14.3)$ & $(0.0)$ & (14.3) & $(0.0)$ & $(0.0)$ & $(0.0)$ & (100.0) \\
\hline \multirow{2}{*}{$971 \sim 980$} & 7 & 3 & 3 & 6 & 0 & 4 & 4 & 2 & 0 & 29 \\
\hline & $(24.1)$ & $(10.3)$ & $(10.3)$ & $(20.7)$ & $(0.0)$ & (13.8) & $(13.8)$ & (6.9) & $(0.0)$ & $(100.0)$ \\
\hline \multirow{2}{*}{$981 \sim 990$} & 8 & 1 & 3 & 2 & 0 & 6 & 1 & 0 & 0 & 21 \\
\hline & $(38.1)$ & $(4.8)$ & $(14.3)$ & (9.5) & $(0.0)$ & (28.6) & (4.8) & $(0.0)$ & $(0.0)$ & $(100.0)$ \\
\hline \multirow{2}{*}{$991 \sim 1000$} & 6 & 4 & 3 & 7 & 0 & 6 & 1 & 1 & 0 & 28 \\
\hline & (21.4) & (14.3) & $(10.7)$ & (25.0) & $(0.0)$ & $(21.4)$ & (3.6) & (3.6) & $(0.0)$ & $(100.0)$ \\
\hline The 10th contus & 56 & 30 & 38 & 40 & 2 & 58 & 9 & 8 & 9 & 244 \\
\hline Ine ruth century & $(23.0)$ & $(12.3)$ & (15.6) & (16.4) & (0.8) & $(23.8)$ & (3.7) & (3.3) & $(1.2)$ & $(100.0)$ \\
\hline
\end{tabular}


Table 1. Continued

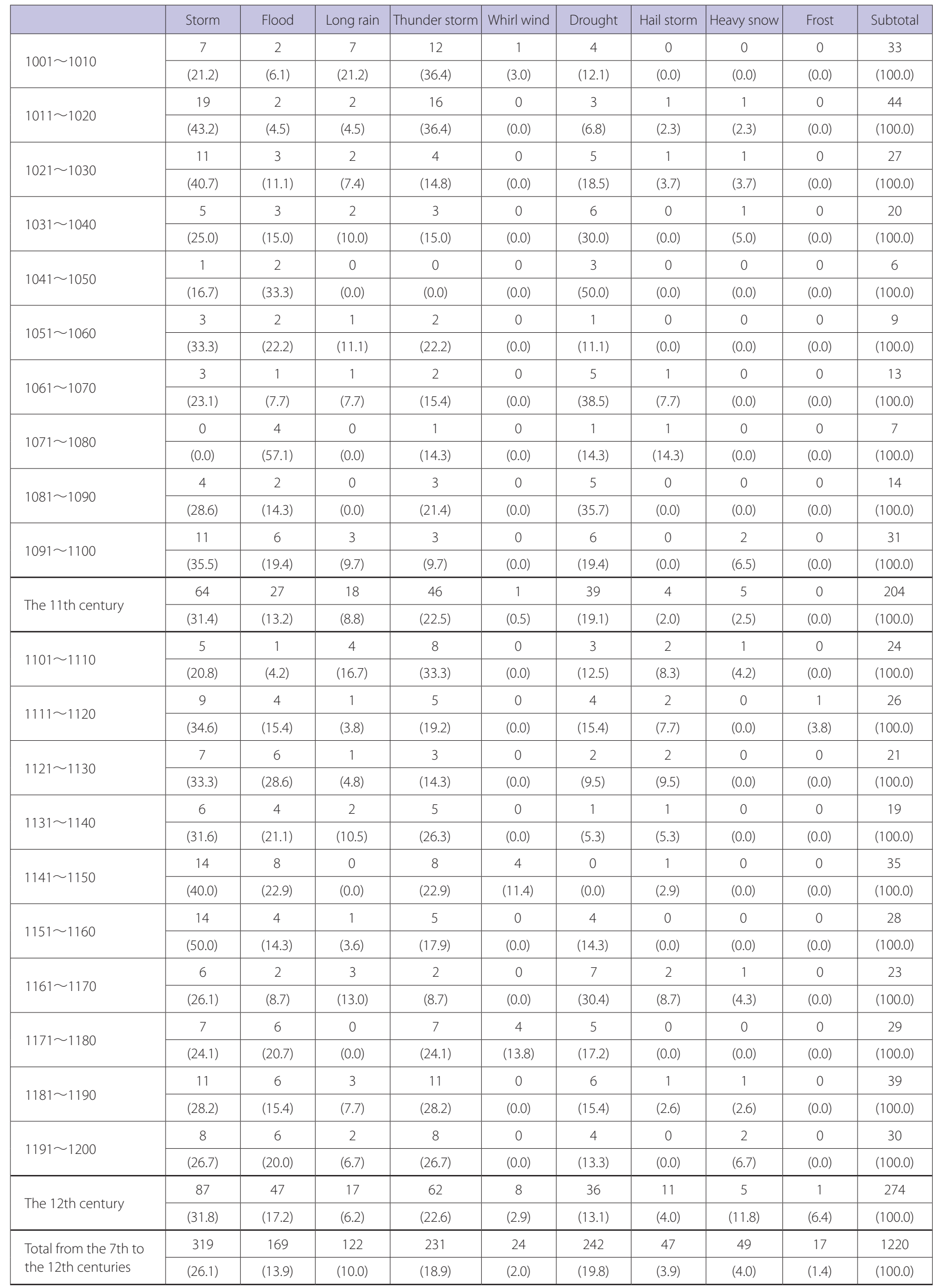


a.

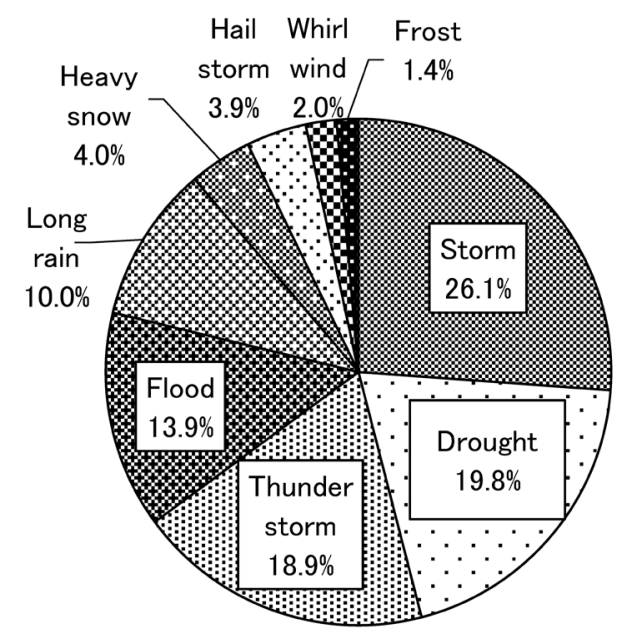

b.

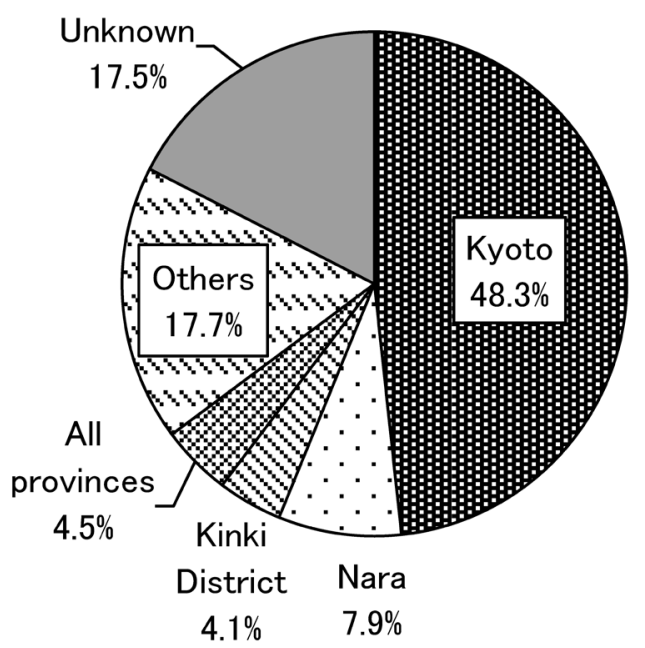

Figure 3. Ratios of kinds of climatic disasters (a) and place names (b) from the 7th to the 12th centuries.

a.

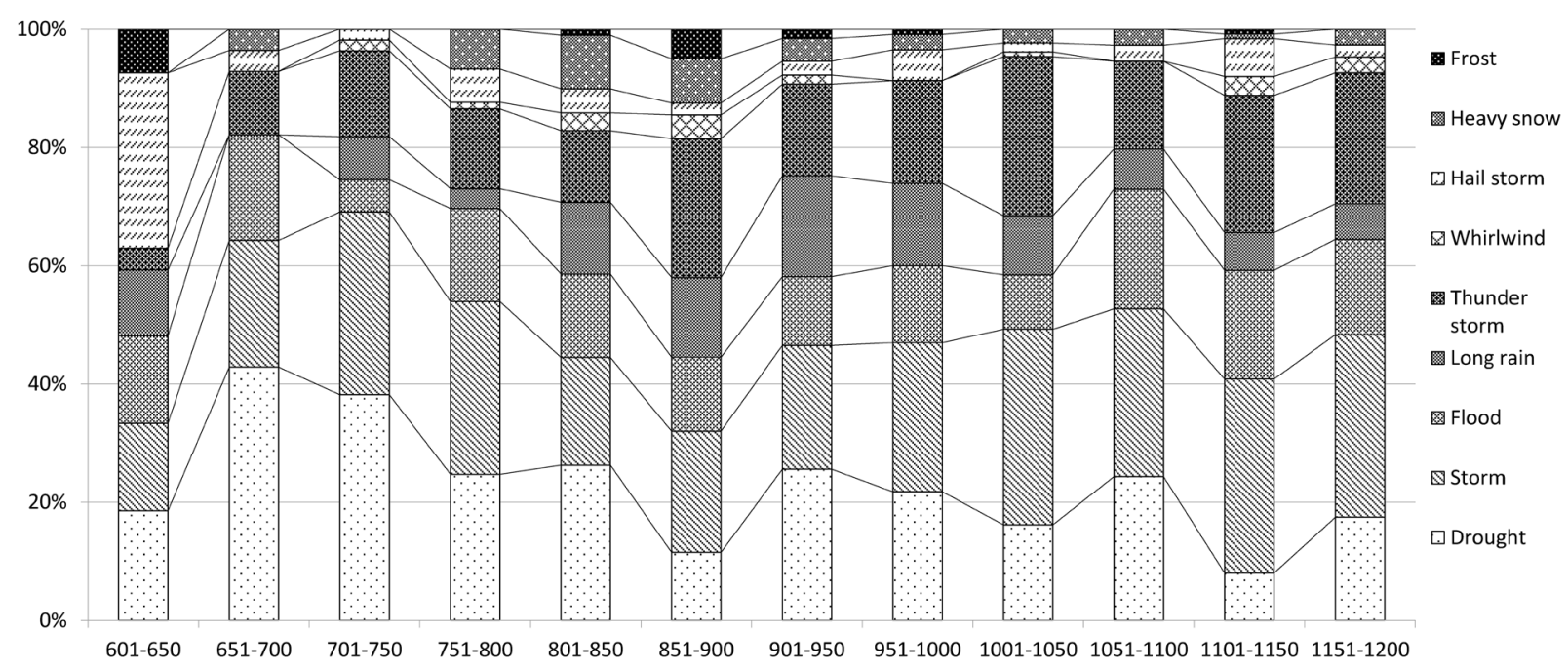

b.

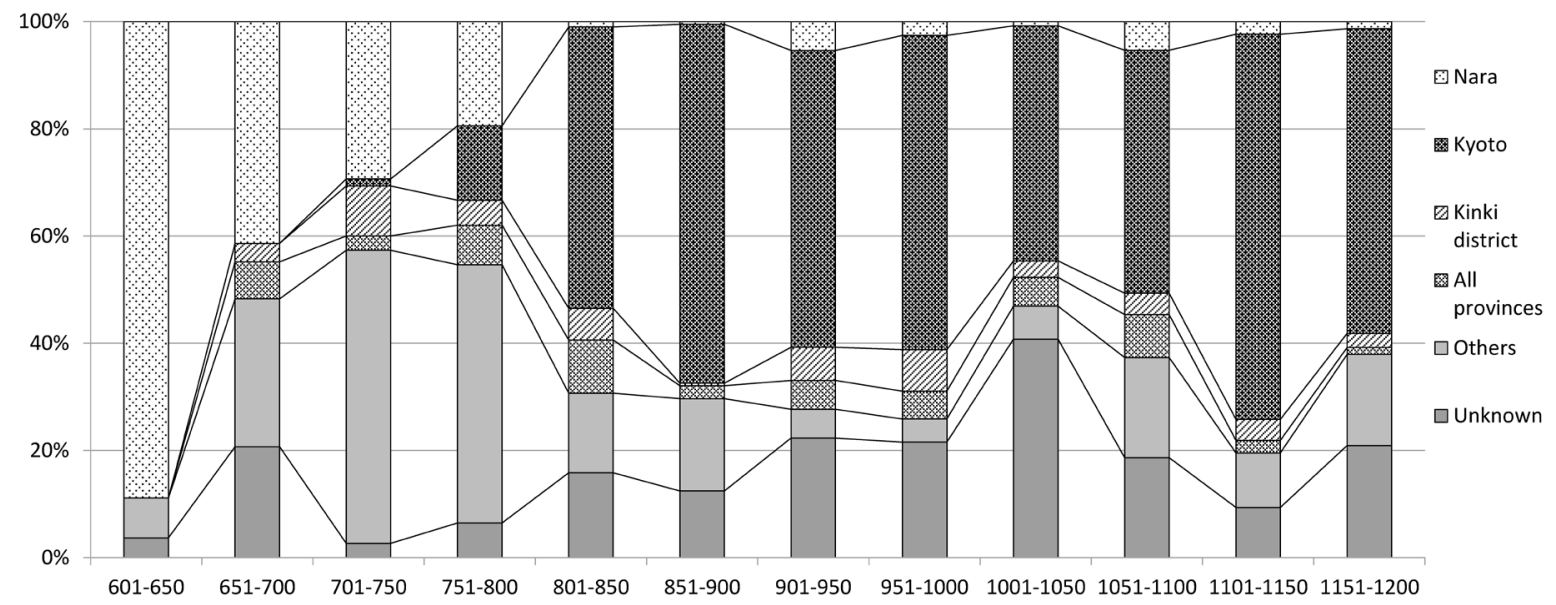

Figure 4. Five decadal changes of percentage on climatic disasters (a) and place names of climatic disasters (b) from the 7th to the 12th centuries. 


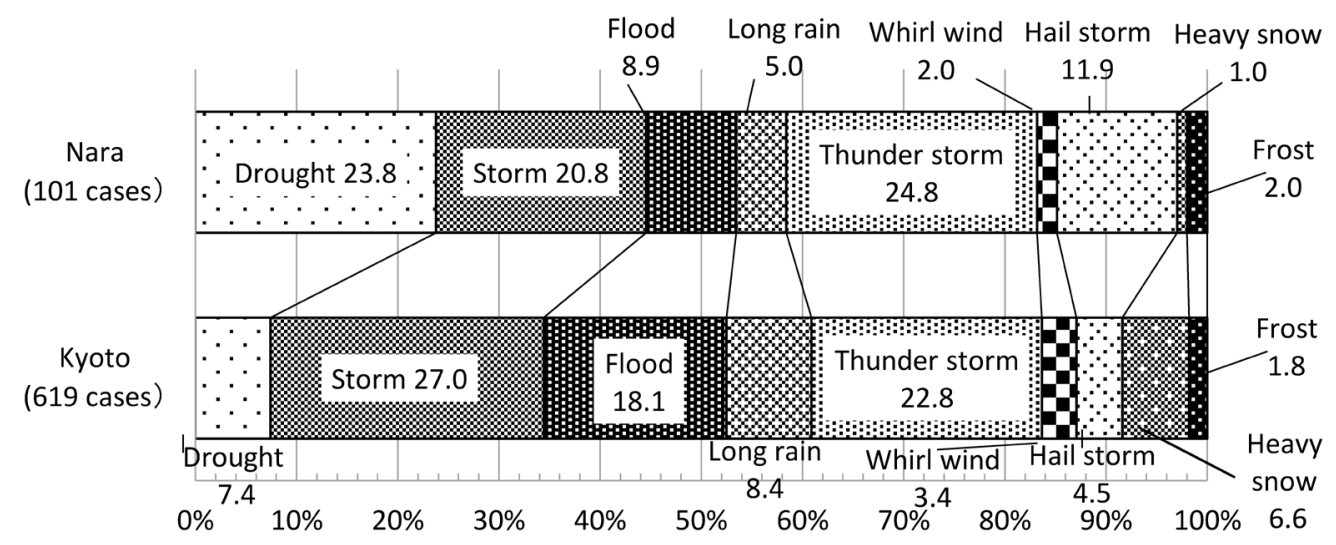

Figure 5. Percentages of climatic disasters from the 7th to the 12th centuries in Nara and Kyoto.

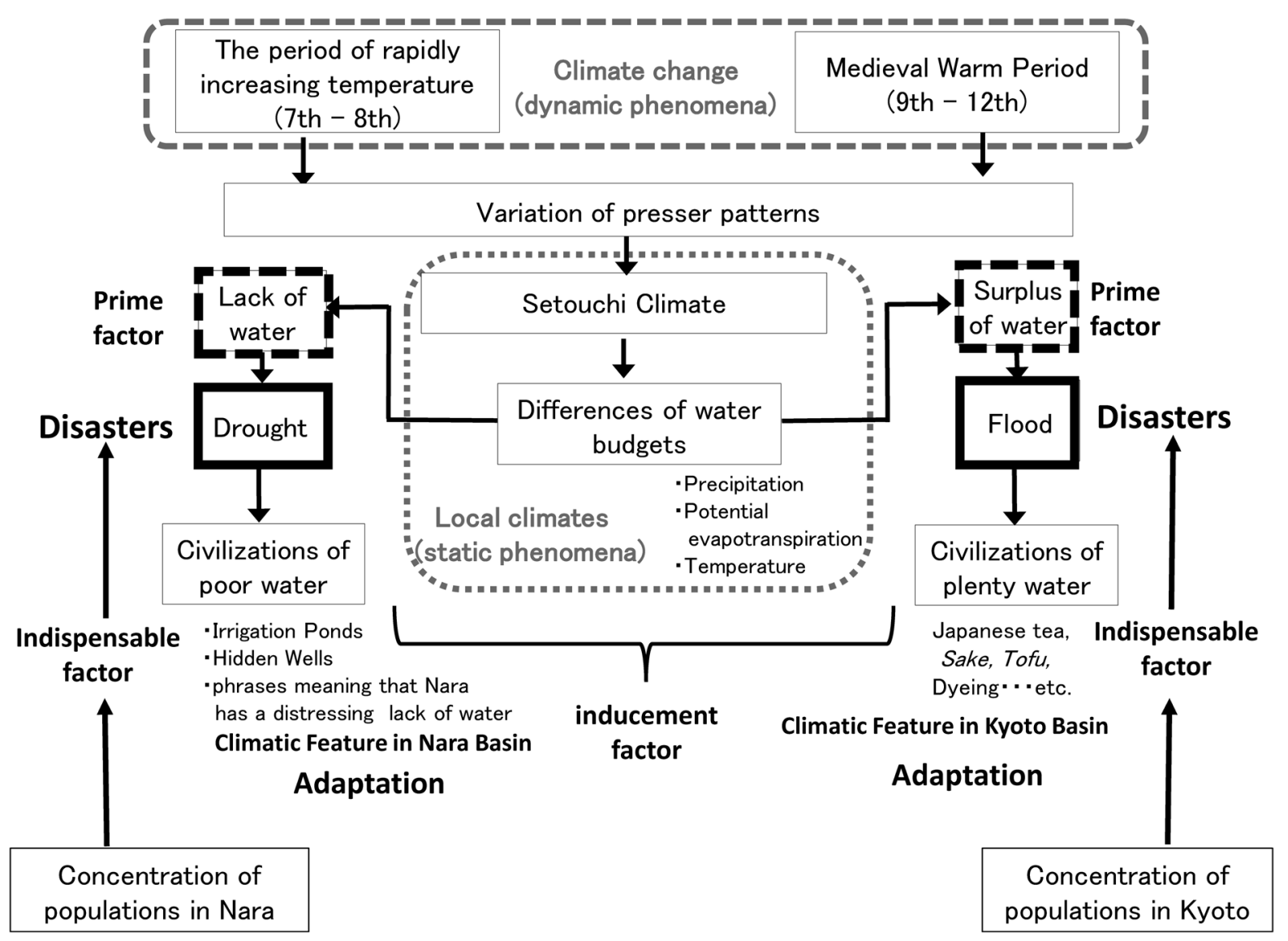

Figure 6. Concept of climatic disasters in Nara and Kyoto from the 7th to the 12th centuries.

in the 8th and 9th centuries whereas long rain brought about principal disaster in the first part of the 9th century from the data of "Rikkokushi" and "Nihon kiryaku". He also stated that the capital in Japan shifted from Nara to Kyoto, which could bring about this result, but he did not refer to their local climates.

Generally, previous studies of the paleoclimate from historical documents have given attention only to climate change. But, it is important to consider that disasters consist of prime, indispensable, induced and expansive factors (Sato et al. 1964). Especially for geographical study, it is valuable to focus on the features of indigenous climate empirically, such as landscapes and water balances.

The Nara and Kyoto basins are located in the east end of the Setouchi climate, according to climatic divisions in Japan (Fukui 1957; Sekiguchi 1959), and have relatively less rain in Japan. From empirical analysis of the present meteorological data, the annual mean of precipitations of Nara and Kyoto (1981-2010) are $1316.0 \mathrm{~mm}$ and $1491.3 \mathrm{~mm}$ respectively. In Nara, more than ten thousand irrigation ponds ${ }^{4}$ were made due to frequently occurred droughts from the ancient times. In "Nihon shoki", some of the irrigation ponds in Nara were made from 607 and 613 (Uchida 2003). Moreover, a number of hidden 
wells were constructed in rice fields in addition to irrigation ponds (Aoki 1961; Nara Local Meteorological Office 1997; Nara Prefecture 2014). Meanwhile, some significant proverbs meaning that Nara had been distressed by lack of water remain such as "Yamato Hideri (weather in Nara is dry)", "Yamato Honen Komekuwazu" which means that it rains properly to fruitful harvest in Nara while poor harvest in other regions is caused by much rain. It is also said that drought has been fateful events in Nara since the dawn of history (Tsujita 1961) and it has brought about a civilization of poor water to the people in Nara, as mentioned above. On the contrary, the Kyoto basin had been frequently tormented with floods by heavy rains from ancient time in spite of belonging to the Setouchi climate. As a matter of fact, the people of Kyoto have suffered Kamogawa River floods frequently since the 8th century (Katahira 2012). In addition, Kyoto is the so-called "metropolis of water" which means that the abundance of water has given rise to cultures such as Japanese tea, sake, tofu, dyeing (Suzuki 2003, 2010).

Furthermore, it was clarified that the occurrence of water deficit in Nara is more than Kyoto and vice versa on water surplus from 1954 to 2012 (Marumoto 2014). Water deficit means the lack of water and water surplus represents the amount of water flowing into soil, ground water and river. That is, Nara shows more remarkably the Setouchi climate than Kyoto. Water deficit in Nara and water surplus in Kyoto could potentially influence their disasters ${ }^{5}$.

Figure 6 shows the concept of components on climatic disasters on paleoclimate from the 7th to the 12th centuries in Nara and Kyoto. Concretely, as shown in this figure, occurrences of disasters need the indispensable factor of human existence and the inducement factor of regional vulnerability. And it would be better to consider that climate change does not cause climatic disaster directly, but lead simply to prime factor of climatic disaster. Therefore, it seems quite probable that the difference of local climates in Nara and Kyoto influenced secular change of climatic disasters in addition to climate change. Needless to say, it could be considered that climatic disasters were caused by other geographical factors such as the concentration of rivers like the Kamogawa River, the Katsuragawa River and others in the case of floods in Kyoto.

Climate usually changes in time and in space, and represents the synthetic condition of atmosphere. Yamakawa (1993) states that a synthetic approach will be needed to reconstruct the paleoclimate. Consequently, it is necessary to give attention not only to climate change but also to various factors such as local climate in order to examine climatic disasters.

\section{Conclusion}

In this study, the authors collected climatic disasters from the 7th to the 12th centuries and obtained 1,220 cases and 1,281 place names. From this database, changes of kinds and regions on climatic disasters were clarified. In consequence, climatic disasters in Japan from the 7th to the 12th centuries are characterized as follows. Climatic disasters increased in the latter half of the 9th century, the first half of the 11th century and the latter half of the 12th century. Drought was the major climatic disaster before the early half of the 9th century and the early half of the 10th century while disaster caused by too much rain prevailed after the latter half of the 9th century except the early half of the 10th century. But the regions with records on climatic disasters clearly changed from Nara to Kyoto at the end of the 8th century because of the move of the capital. Therefore, the authors proposed that there are differences of local climate in the climatic disasters in Nara and Kyoto.

Consequently, it is important to take notice of geographical factors such as indigenous local climate and landscape for elucidating climatic disasters in the historical period and a more holistic viewpoint is needed. Since geography is integrative and interactive study, it is necessary to consider not only climate change but also various geographical factors in order to elucidate the environment in any historical period.

\section{Acknowledgements}

We would like to express our gratitude to Prof. Peter Riley for checking English and Prof. Yamakawa Shuji (Nihon Univ.) and Prof. Sergey Varlamov and Prof. Nina Dashko for their valuable comments.

This study was presented at the Study Meeting of The Association of Japanese Geographers Autumn 2014 (September 20-22, 2014 Toyama Univ.). We would like to thank also members who advised us at the meeting.

\section{Notes}

1. According to The Central Meteorological Observatory and The Imperial Marine Observatory (1976), the storm means heavy rain with gale. In addition, in case of simply gale occurred in one district while heavy rain with flood observed in other district, this record is adopted the storm. However, thunder storm and whirlwind are excluded. The flood represents some damages from both 
heavy rain and long rain without gale. Furthermore flood caused by storm or thunder storm is excluded to avoid duplication. The thunder storm consists of lightning with hailstone, gale or heavy rain which is able to bring about disaster. However, thunder storm with whirlwind is classified as the whirlwind. The whirlwind contains mainly tornado and include the episode of dragon, serpent or "Mizuchi" (imaginary animal like dragon or serpent) because these animals were considered that they were related to tornado in ancient time. Moreover, singular wind as "Shofu" or "Ichimokuren" (such as blast) is also classified into the whirlwind. Drought means that no rainfall continued from one to several months. And a few records of prayers for rain are also counted to the drought. Rainfall that goes on as long as a month or more is added to the long rain if they caused disaster. However, the long rain that obviously caused flood is classified into the flood to keep out duplication. The heavy snow involves the case of the snowfall more than 1 shaku (about $30.3 \mathrm{~cm}$ ) around Kinki and Kanto districts. In case of hail storm which caused disaster, the case is classified mainly into the hail storm. But the hail storm with thunder is classified into the thunder storm.

2. Kusakabe (1977) counted only climatic disasters that occurred in two or more regions from "Nihon no kisho shiryo". Nishikawa (1968) used just "Nihon sai $i$ shi" for counting climatic disasters. For these reasons, their disaster's data are less than ours. These data were excluded epidemic, famine, volcanic eruption and tsunami from their original data.

3. The authors did not consider the periods of Naniwa kyo, Kuni kyo and Shigaraki kyo in this study because each of the periods were short (estimated less than ten years) and the established periods are not clear. In addition, the period when Kyoto was capital is estimated until 1192 or 1185 . In this study, the authors used 1192 as the end of the period.

4. According to Hall (1932), there were 10,056 irrigation ponds in the Nara basin in the first half of the 20 century and $70.9 \%$ of the region was irrigated. On the details of irrigation region, it is said that the regions irrigated by ponds, rivers and wells were $72.4 \%$, $25.6 \%$, and $1.6 \%$, respectively.

5. From "Nihon kisho saigai nempyo" (The Central Meteorological Observatory 1949; Japan Meteorological Agency 1960), the climatic disasters occurred 30 times in Nara and 48 times in Kyoto from 1900 to 1952. In these results, the disasters due to droughts occupied $30.0 \%$ in Nara but the ones in Kyoto were only $13.0 \%$ and the disasters due to floods in Nara were $63.3 \%$ whereas the ones in Kyoto were 69.6\%. However, the river environments such as embankment changed from the ancient time.

\section{References}

Aoki, S. 1956. Naraken kisho saigai shi. Nara: Yotokusha. (J)

Aoki, S. 1961. Naraken ni okeru kiko to saigai. In Nara bonchi, ed. Department of Geography, Nara Women's University, 28-44. Tokyo: Kokon Shoin. (J)

Aono, Y. 2013. Climate reconstruction by using of cherry blossom phenological data in Kyoto. Historical Geography 55(5): 48-52. (JE)

Arakawa, H., Osumi, K. and Tamura, K. 1964. Nihon kanbatsu rin-u shiryo. Tokyo: Meteorological Research Institute. (J)

Fukui, E. 1957. Nihon ni okeru Thornthwaite no shin kiko kubun. Tokyo Geography Papers 1: 101-112. (J)

Geospatial Information Authority of Japan 2000. Kinkichiho no kochiri ni kansuru chosa sagyo hokokusho. Tsukuba. (J)

Hall, B. R. 1932. The Yamato basin, Japan. Annals of the Association of American Geographers 22: 243-293.

Hotate, M. 2012. Rekishi no naka no daichidoran: Nara Heian no jishin to tennou. Tokyo: Iwanami Shoten. (J)

IPCC and Ministry of the Environment, Government of Japan 2013. Climate Change 2013 (AR5) from IPCC Report, The Physical science basis. http://www.env.go.jp/earth/ ipcc/5th/pdf/ar5_wg1_overview_presentation.pdf (last accessed 24 August 2016) (J)

Japan Meteorological Agency 1960. Nihon kisho saigai nempyo 1948-1959. Tokyo: Japan Weather Association.

Japan Meteorological Agency 2013. Fifth Assessment Report: Climate Change 2013 (AR5) from IPCC Report, The physical science basis. http://www.data.jma.go.jp/cpdinfo/ipcc/ar5/ ipcc_ar5_wg1_spm_jpn.pdf (last accessed 24 August 2016) (J)

Katahira, H. 2010. Heiankyo no saigai emaki: Mizu no shurai to hi no rensa. In Kyo no fudo to keikan, ed. Department of Literature, Ritsumeikan University, 28-47. Kyoto: Shirakawa Shoin. (J)

Katahira, H. 2012. 17 seiki kohan ni okeru kamogawa no kozui to teibo no kensetsu. In Kyoto no rekishisaigai, ed. A. Yoshikoshi and H. Katahira, 46-63, Kyoto: Shibunkaku. (J)

Kawasumi, T. 2004. Rekishijidai ni okeru Kyoto no kozui to hanrangen no chikeihenka Iseki ni kirokusareta saigaijoho wo mochiita suigaishi no saikouchiku. Historical Disaster Studies in Kyoto 1: 13-23. (J)

Kitagawa, H. and Matsumoto, E. 1998. Yakusugi nenrin no tanso doitaihi hendo kara suiteisareru kako 2000 nenkan no kikohendo. Meteorological Research Notes 191: 1-13. (J)

Kusakabe, M. 1969. 19 seikimatsu made no Shikoku no kishosaigai. Journal of Meteorological Research 20: 502-526. (J)

Kusakabe, M. 1973a. 19 seikimatsu made no Kanto chiho no kishosaigai 1. Journal of Meteorological Research 25: 385-403. (J)

Kusakabe, M. 1973b. 19 seikimatsu made no Kanto chiho no kishosaigai 2. Journal of Meteorological Research 25: 429-447. (J)

Kusakabe, M. 1975a. 19 seikimatsu made no Chubu chiho oyobi Mieken no kishosaigai 1. Journal of Meteorological Research 27: 81-96. (J)

Kusakabe, M. 1975b. 19 seikimatsu made no Chubu chiho oyobi Mieken no kishosaigai 2. Journal of Meteorological Research 27: 119-135. (J)

Kusakabe, M. 1975c. 19 seikimatsu made no Chubu chiho oyobi Mieken no kishosaigai 3. Journal of Meteorological Research 27: 159-173.

Kusakabe, M. 1975d. 19 seikimatsu made no Chubu chiho oyobi Mieken no kishosaigai 4. Journal of Meteorological Research 27: 203-217.

Kusakabe, M. 1977. 19 seikimatsu made no Kinki chiho no kishosaigai. Journal of Meteorological Research 29: 1-50. (J)

Kusakabe, M. 1978. 19 seikimatsu made no Chugoku chiho no kishosaigai. Journal of Meteorological Research 30: 23-56. (J)

Kusakabe, M. 1981. 19 seikimatsu made no Ou chiho no kishosaigai. Journal of Meteorological Research 33: 89-133. (J)

Kyoto Local Meteorological Office 1951. Kyoto kisho saigai nempyo. Kyoto. (J)

Maejima, I. and Tagami, Y. 1986. Climatic change during historical times in Japan: Reconstruction from hazard records. Geographical Reports of Tokyo Metropolitan University 21: 157-171. 
Marumoto, M. 2014. Hydro-climatological features in Nara and Kyoto basins: Year climatic analysis by Thornthwaite's method. Quarterly Journals of Geography (Kikan Chirigaku) 66: 82-93. (JE)

Mizukoshi, M. 2004. Kokiroku ni yoru 16 seiki no tenkokiroku. Tokyo: Tokyodo Shuppan. (J)

Mizukoshi, M. 2006. Kokiroku ni yoru 15 seiki no tenkokiroku. Tokyo: Tokyodo Shuppan. (J)

Mizukoshi, M. 2008. Kokiroku ni yoru 14 seiki no tenkokiroku. Tokyo: Tokyodo Shuppan. (J)

Mizukoshi, M. 2010. Kokiroku ni yoru 13 seiki no tenkokiroku. Tokyo: Tokyodo Shuppan. (J)

Mizukoshi, M. 2012. Kokiroku ni yoru 12 seiki no tenkokiroku. Tokyo: Tokyodo Shuppan. (J)

Mizukoshi, M. 2014. Kokiroku ni yoru 11 seiki no tenkokiroku. Tokyo: Tokyodo Shuppan. (J)

Nara Local Meteorological Office 1997. Naraken no kisho hyakunen. Nara: Ministry of Finance, Japan. (J)

Nara Prefecture 2014. Yoshinogawa bunsui mizu to no tatakai: Yamatoheiya ni okeru samazamana kufu. http://www.pref. nara.jp/dd.aspx?menuid $=12078$. (last accessed 24 August 2016) (J)

Nishikawa, O. 2002. Nihonkan to shizenkankyo. Tokyo: Akatsukiin Shokan. (J)

Nishikawa, Y. 1968. The studies of history on disaster in Japan. Journal of Japan Society of Engineering Geology 9: 129-136. (J)

Okamura, Y. 2012. Reconstruction of the 869 Jogan tsunami and lessons of the 2011 Tohoku earthquake: Significance of ancient earthquake studies and problems in announcing study results to society. Synthesiology 5: 234-242. (JE)

Sangawa, A. 2013. Rekishi kara saguru 21 seiki no kyodaijishin. Tokyo: Asahi Shimbun Publications. (J)

Sato, T., Okuda, Y. and Takahashi, Y. 1964. Saigai ron. Tokyo: Keiso Shobo. (J)

Sekiguchi, T. 1959. Climatic regions in Japan. Tokyo Geography Papers 3: 65-78. (JE)
Sekiguchi, T. 1969. The historical dates of Japanese cherry festivals since the 8 th century and her climatic changes. Tokyo Geography Papers 13: 175-190. (JE)

Suzuki, M. 2003. Motto shiritai mizu no miyako Kyoto. Kyoto: Jimbunshoin. (J)

Suzuki, M. 2010. Mizu ga kataru kyo no miyako no kurashi densetsu, meisui, shoku no bunka. Kyoto: Shirakawa Shoin. (J)

Takahashi, M. 2012. Kinsei ni okeru Kyoto Kamogawa, Katsuragawa no suigai. In Kyoto no rekishisaigai, ed. A. Yoshikoshi and $\mathrm{H}$. Katahira, 33-45, Kyoto: Shibunkaku. (J)

Tanioka, T. 2010. Climate variations of summer half-years from the 7 th to 10th century in the Kinki region, west central Japan based on historical documents. Geographical Review of Japan 83: 44-59. (JE)

The Central Meteorological Observatory 1949. Nihon kisho saigai nempyo 1900-1947. Tokyo.

The Central Meteorological Observatory and The Imperial Marine Observatory 1976. Nihon no kishoshiryo (1)-(3). Tokyo: Hara Shobo. (J)

The Civic Section of Tokyo Metropolitan Government 1976. Nihon no tensai chihen. Tokyo: Hara shobo. (J)

Tsujita, U. 1961. Nara bonchi no chirigakuteki kenkyu. In Nara bonchi, ed. Department of Geography, Nara Women's University, 12-27. Tokyo: Kokon Shoin. (J)

Uchida, K. 2003. Nihon no tameike. Shiga: Kaiseisha. (J)

Yamakawa, S. 1993. Natural disasters and climatic variations in Little ice age. Journal of Geography (Chigaku Zasshi) 102: 183-195. (JE)

Yamamoto, T. 1976. Kiko no kataru Nihon no rekishi. Tokyo: Soshiete. (J)

Yoshino, M. 2009. Climatic change and human activities in the 4th to 10th centuries. Journal of Geography (Chigaku Zasshi) 118: 1221-1236. (JE)

(J) written in Japanese

(JE) written in Japanese with English abstract 